\title{
Staff and family attitudes to keeping joint medical and nursing notes at the foot of the bed: questionnaire survey
}

\author{
S G M Luke, A Gallagher, B W Lloyd
}

Some years ago we introduced joint medical and nursing notes in our children's department. ${ }^{1}$ In 1995, to promote openness and teamwork with families, we started placing these notes at the foot of the bed and encouraged parents to read them. We evaluated this innovation.

\section{Methods and results}

We distributed questionnaires to all doctors and qualified nurses who had been working on the children's wards for at least three months. We asked staff to list up to three advantages and three disadvantages of keeping notes at the foot of the bed. On about 10 occasions SGML visited the wards and distributed a questionnaire to all English speaking parents present at the time. Parents were asked about their experiences of reading their child's notes and whether the practice of keeping notes at the foot of the bed should be continued. She collected the questionnaires after about 30 minutes.

All 35 questionnaires given to nursing staff and 36 of the 39 questionnaires given to doctors were returned. Staff cited similar numbers of advantages and disadvantages (table).

Ten members of staff had seen an unauthorised person (usually a family member other than parents) reading the notes. However, despite prompting, no member of staff reported any problems arising from these episodes. Concern about previous hospital attendances being overlooked arose because the old notes were kept in the ward office, not at the foot of the bed.

Altogether, 105 of the 110 parental questionnaires were returned. Sixty six parents had read their child's notes "thoroughly" and 25 had read them "briefly." Seventy five parents felt better informed about their child's progress. Fourteen parents valued the openness of the innovation, and 12 reported that the innovation involved them in decision making.

Seventy eight parents were "not worried" about someone unauthorised reading the notes, 17 were "slightly worried," and 8 were "very worried." Seventy

Advantages and disadvantages of having notes at foot of bed, reported in questionnaire survey by 71 doctors and nurses

\begin{tabular}{lc} 
& No of citations \\
\hline Advantages: & \\
\hline Parental involvement in care of child or openness & 61 \\
\hline Easy access to notes & 37 \\
\hline Better medical care & 18 \\
\hline People will think before they write & 2 \\
\hline Disadvantages: & 59 \\
\hline Concerns about confidentiality & 19 \\
\hline Misinterpretation of notes by family & 16 \\
\hline Fear of loss or damage to notes & 11 \\
\hline Concern about previous notes being forgotten & 5 \\
\hline Inhibition about writing freely & 1 \\
\hline Cannot do "casenote ward rounds"
\end{tabular}

four parents who read the notes found them "very helpful." Most (102) parents stated that they would like to see the innovation continued. Three parents suggested that the notes should be kept in the child's bedside locker.

\section{Comment}

The perceived benefits of openness and increased involvement of parents in their child's care seemed to outweigh concerns about confidentiality because most staff and parents wanted to continue keeping the notes at the foot of the bed. Some doctors and nurses might have written responses that they thought would please us. Also, we do not know how different the responses from parents would have been if they had been interviewed by an independent researcher after their child's discharge.

We have not investigated the effect of our innovation on what is written in the notes. Our policy has been that observations about sensitive matters should be written in the notes at the foot of the bed if they can be written in a way that is not likely to cause offence. Occasionally some observations, including some written by social workers and psychiatrists, are written on sheets kept in the child's folder in the ward office. Similarly, when concerns exist about child protection, we believe that it is sometimes in the child's best interests to keep all notes in the ward office. These variations from standard practice have not caused any obvious problems.

It is 25 years since Shenkin and Warner proposed giving patients their own medical records. ${ }^{2}$ Since then, patient held records have sometimes been used outside hospital. ${ }^{3}$ In 1986 Baldry and colleagues reported the benefits of giving patients in a general practice their case notes to read while they were waiting for an appointment. ${ }^{5}$ We could not find any studies in which inpatients have been encouraged to read their notes. Our results suggest that keeping notes by the child's bed promotes partnership with parents. Staff working in other specialties could consider following our example.

Contributors: All authors designed the study and wrote the paper. SGML collected and analysed the data; AG collected the data; and BWL analysed the data and is the guarantor for the paper.

Funding: None.

Competing interests: None declared.

1 Robins A, Gallagher A, Rossiter MA, Lloyd BW. Evaluation of joint medical and nursing notes with preprinted prompts. Qual Health Care 1997:6:192-3.

2 Shenkin BN, Warner DC. Giving the patient his medical record: a proposal to improve the system. NEngl J Med 1973;289:688-92.

3 Elbourne D, Richardson M, Chalmers I, Waterhouse I, Holt E. The Newbury maternity care study: a randomised controlled trial to assess a policy of women holding their own obstetric records. Br J Obstet Gynaecol 1987;94:612-9.

4 O'Flaherty S, Jandera E, Llewellyn J, Wall M. Personal health records: an evaluation. Arch Dis Child 1987;62:1152-5.

5 Baldry M, Cheal C, Fisher B, Gillett M, Huet V. Giving patients their own records in general practice: experience of patients and staff. $B M$ J 1986;292:596-8.

(Accepted 25 February 1999)
Children's

Department, North Middlesex Hospital, London N18 1QX S G M Luke, paediatric senior registrar A Gallagher, clinical nurse specialist B W Lloyd, consultant paediatrician Correspondence to Dr Lloyd, Child Health, Royal Free Hospital, London NW3 2QG

blloyd@rfhsm.ac.uk

BMJ 1999;319:735 